\title{
Roles of physical exercise in neurodegeneration: reversal of epigenetic clock
}

\author{
Miao Xu ${ }^{1,2}$, JiaYi Zhu ${ }^{2,6}$, Xian-Dong Liu ${ }^{2,3}$, Ming-Ying Luo ${ }^{1}$ and Nan-Jie $X u^{2,4,5^{*}}$ (B)
}

\begin{abstract}
The epigenetic clock is defined by the DNA methylation (DNAm) level and has been extensively applied to distinguish biological age from chronological age. Aging-related neurodegeneration is associated with epigenetic alteration, which determines the status of diseases. In recent years, extensive research has shown that physical exercise (PE) can affect the DNAm level, implying a reversal of the epigenetic clock in neurodegeneration. PE also regulates brain plasticity, neuroinflammation, and molecular signaling cascades associated with epigenetics. This review summarizes the effects of PE on neurodegenerative diseases via both general and disease-specific DNAm mechanisms, and discusses epigenetic modifications that alleviate the pathological symptoms of these diseases. This may lead to probing of the underpinnings of neurodegenerative disorders and provide valuable therapeutic references for cognitive and motor dysfunction.
\end{abstract}

Keywords: Physical exercise, DNA methylation, Neural mechanism, Neurodegeneration, Motor deficits

\section{Background}

The lack of physical exercise (PE) is a common phenomenon in modern society and has become a risk factor for many diseases, including cardiovascular diseases, metabolic dysfunctions, cancers, and neurodegenerative diseases [1-3]. In recent years, regular PE-whether aerobic exercise, anaerobic exercise, or resistance exercise-has been recommended as an essential component of healthy lifestyles. Appropriate exercise shapes the athletic figure and improves the body's basal metabolic rate [4]. PE also plays a vital role in brain health, especially in preventing and alleviating the decline of cognitive function as well as the occurrence of some neurodegenerative diseases [5, 6]. Due to the extensive impacts of brain health and the benefits of PE to physical fitness, systematic reviews and

\footnotetext{
*Correspondence: xunanjie@sjtu.edu.cn

${ }^{2}$ Collaborative Innovation Center for Brain Science, Department

of Anatomy and Physiology, Shanghai Jiao Tong University School of Medicine, Shanghai 200025, China

Full list of author information is available at the end of the article
}

meta-analyses have emerged to sum up the possible connections, bringing us insightful conclusions with quantitative evidence $[7,8]$.

In healthy brain conditions, basic cognitive functions promote advanced brain competencies such as language skill, strategy learning, executive capability, and reasoning, which are essential for the development and progression of human society $[9,10]$. Cognitive decline is often observed in rapidly aging populations [11], and in many cases, can progress to mild cognitive impairment or dementia with diagnosis of neurodegenerative diseases such as Alzheimer's disease (AD) and Parkinson's disease (PD) $[12,13]$. Therefore, topics around cognitive decline and neurodegenerative diseases during both normal and abnormal brain aging have become one of the leading issues on health. Several authoritative healthrelated research agencies including the National Institute on Aging in the U.S. Department of Health \& Human Services have suggested the unequivocal effect of appropriate $\mathrm{PE}$ in improving cognition across populations original author(s) and the source, provide a link to the Creative Commons licence, and indicate if changes were made. The images or other third party material in this article are included in the article's Creative Commons licence, unless indicated otherwise in a credit line to the material. If material is not included in the article's Creative Commons licence and your intended use is not permitted by statutory regulation or exceeds the permitted use, you will need to obtain permission directly from the copyright holder. To view a copy of this licence, visit http://creativecommons.org/licenses/by/4.0/. The Creative Commons Public Domain Dedication waiver (http://creativeco mmons.org/publicdomain/zero/1.0/) applies to the data made available in this article, unless otherwise stated in a credit line to the data. 
(including children, adolescents, and older adults). The positive effects of regular, long-term physical activities and exercise interventions on cognition have also been reported in the literature $[14,15]$. Since only limited therapies are available for cognitive impairment, exercise may serve as a promising non-pharmaceutical treatment [16].

For the past few years, the process of brain aging, which is one of the risk factors for neurodegeneration, has been found to involve epigenetic mechanisms [17]. Epigenetics, by definition, refers to a set of heritable mechanisms and phenomena that determine cell phenotypes without changing the genome [18]. Epigenetic modifications such as abnormal DNA methylation (DNAm), microRNAs and histone modifications are closely associated with damage to brain health and neurodegenerative diseases [17]. DNAm is a fundamental epigenetic modification that coordinates gene expression, and its level has been regarded as a mark for age prediction [19]. As individuals age, the age-related changes are often linked to the fluctuating methylation levels of specific genes. The DNAm has been proposed as a potential muti-tissue estimator of biological age and the concept of epigenetic clock (i.e., DNAm clock) has been developed with a suitable regression model to systemically measure the biological age in all tissues and cell types except the sperm [20]. This tool has been extensively applied to distinguish between chronological age and biological age, as well as to estimate the corresponding health/disease status [21, 22]. While healthy individuals have almost identical chronological age and biological age (normal aging), patients with cancer and neurodegenerative diseases are biologically older (pathologic aging) and the offspring of centenarians are biologically younger (delayed aging) [21, 23, 24]. Therefore, the epigenetic clock is capable of assessing the state of aging among populations. Moreover, DNAm is associated with environmental and lifestyle factors, which have the capacity for regulating epigenetic variability in the brain $[25,26]$. Given the effects of such factors as PE in slowing down the epigenetic age acceleration or even resetting the aging clock, the epigenetic clock has progressively become an exciting area of research [22]. In addition, these factors offer a possibility not only to delay disease progression and pathological aging, but also to promote rejuvenation. Therefore, PE has potentials to reverse the epigenetic clock against neurodegeneration (Fig. 1).

In this review, we summarize brain-specific, diseaserelated mechanisms involving DNAm (Table 1), through which PE reverses the epigenetic clock to ameliorate neurodegeneration in aging, $\mathrm{AD}$, and $\mathrm{PD}$ (Table 2). We also integrate data from muscular-related molecule cascades in the periphery, which are directly induced by PE to affect the central nervous system (CNS). Furthermore, as a potential mediator of motor skills, DNAm can be modulated to improve the pathological symptoms of dyskinesia-related neurodegenerative diseases. The role of PE in neurodegeneration is further explored from the perspective of epigenetic-related mechanisms, and PE can be viewed as a potential rejuvenation therapy.

\section{Epigenetic regulation during aging and neurodegeneration}

It is generally acknowledged that brain aging is distinct from neurodegenerative diseases-brain aging is a physiological condition whereas neurodegeneration is pathological. However, the two phenomena are interrelated since most aging adults would eventually encounter neurodegeneration, whose onset and progression are influenced by genetic and environmental factors. Therefore, aging is considered as a risk factor for the cognitive decline associated with neurodegenerative diseases whereas neurodegeneration is the manifestation of accelerated aging [27]. In normal brain aging, cognitive function gradually declines. In neurodegenerative disorders, the decrease in cognitive function is not the only symptom observed; major symptoms also include progressive damage in learning and memory, which could eventually lead to dementia. In addition, neuronal apoptosis is a natural physiological process that mediates controlled cell death. Although normal brain aging is regarded as an environmental factor contributing to apoptosis, the course of this process can be drastically accelerated in neurodegenerative diseases. Consequently, to some extent, the two conditions have similarities in symptoms and manifestations (e.g., memory and learning deficits) and the leading pathological features (e.g., neuronal death) [28].

As mentioned above, DNAm can not only predict the biological age due to its associations with brain aging, but is also involved in neurodegenerative diseases, implying its use to better visualize the pathogenesis. For example, in $\mathrm{AD}$, the typical pathological features for diagnosis are senile plaque formation and neurofibrillary tangles (NFTs). The senile plaques are primarily formed from the deposition of beta amyloid $(A \beta)$ proteins due to the abnormal shearing of amyloid precursor proteins (APPs) while the formation of NFT results from excessive phosphorylation and aggregation of tau proteins [29]. These neuropathological biomarkers of $\mathrm{AD}$ have been confirmed to be present in epigenetic age acceleration [30]. The accelerated aging caused by $\mathrm{AD}$ can be reflected by DNAm. For example, in a recent study, the DNAm age was shown to be 9 years older than the chronological age in an offspring of monozygotic triplets, who developed early-onset AD at age 50 [31]. Therefore, the accelerated epigenetic clock is associated with these 


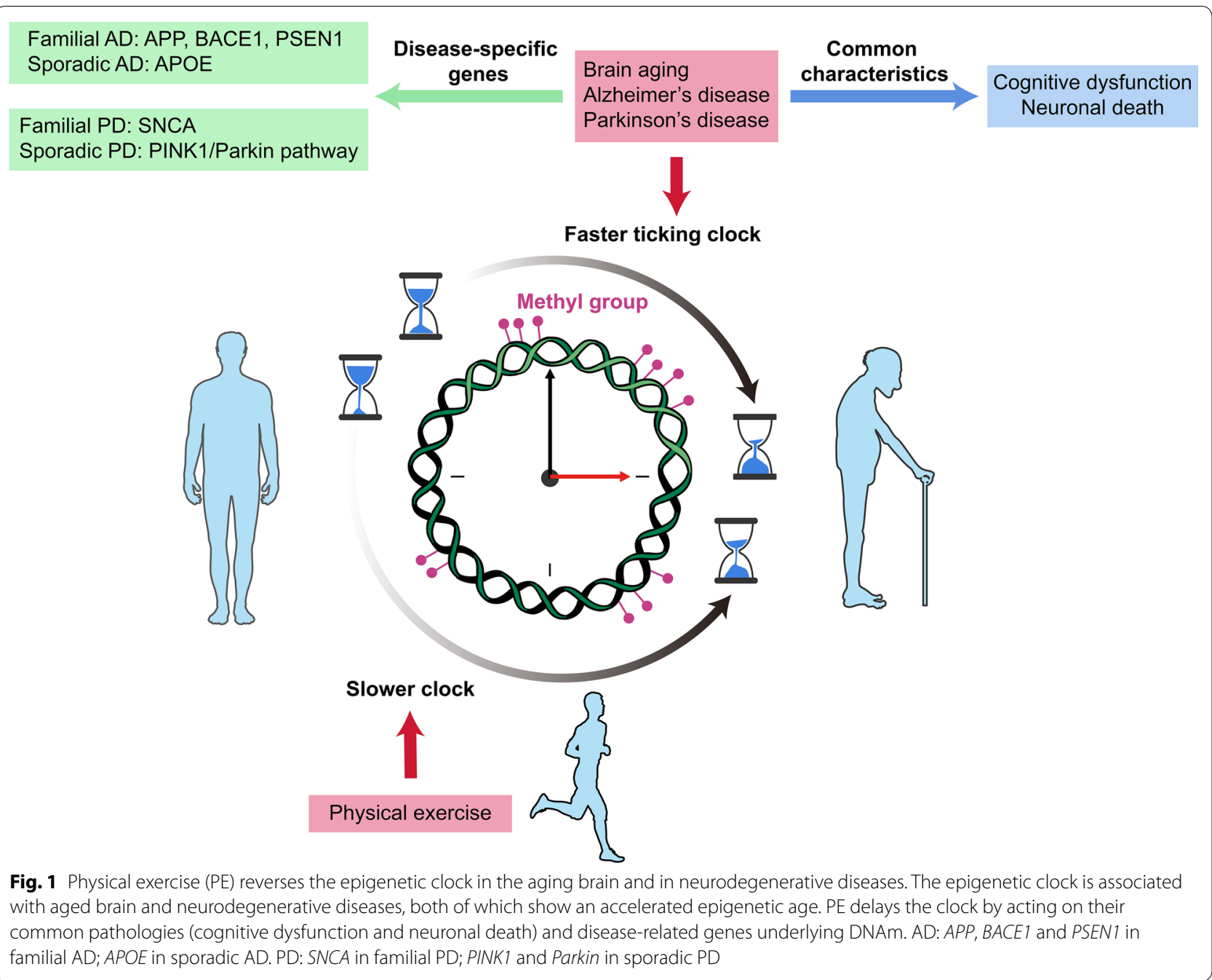

Table 1 Regulation of DNAm during neurodegeneration

\begin{tabular}{|c|c|c|c|}
\hline References & Samples/subjects & Conditions & DNA methylation changes \\
\hline Tan et al. [42] & $5 \mathrm{ml}$ blood samples of patients with PD & PD & CpG-2 of SNCA is hypomethylated \\
\hline Cronk et al. [122] & $\begin{array}{l}\text { C57BI/6 J } \\
\text { MeCP2-null mice }\end{array}$ & Rett syndrome & $\begin{array}{l}\text { MeCP2 regulates microglial responsiveness } \\
\text { and inflammatory gene transcription }\end{array}$ \\
\hline McKinney et al. [83] & $\begin{array}{l}\text { Postmortem orbital frontal cortices from } 22 \\
\text { individuals (age }>60 \text { years) }\end{array}$ & Brain aging & $\begin{array}{l}\text { Ten of } 26 \mathrm{CpG} \text { loci in BDNF are hypermethyl- } \\
\text { ated }\end{array}$ \\
\hline Tarale et al. [45] & Human neuroblastoma cell line & PD & PARK 2 and PINK1 are hypermethylated \\
\hline Xie et al. [157] & $\begin{array}{l}\text { Whole-blood samples from } 506 \mathrm{aMCl} \\
\text { patients }\end{array}$ & $A D$ & $\begin{array}{l}\text { Peripheral BDNF promoter methylation is } \\
\text { elevated }\end{array}$ \\
\hline Gontier et al. [133] & Aged (18-month-old) male C57BL/6 mice & Brain aging & $\begin{array}{l}\text { Decreased Tet } 2 \text { expression and } 5 \text {-hmC levels } \\
\text { in the aged hippocampus }\end{array}$ \\
\hline Li et al. [8] & Individuals (Female: 47; Male: 54) & $A D$ & $\begin{array}{l}\text { Hypomethylated enhancers in the DSCAML1 } \\
\text { gene that targets BACE1 }\end{array}$ \\
\hline Balasubramanian et al. [119] & Adult male Wistar rats & Mild traumatic brain injury & Hypermethylation at SOD2 promoter \\
\hline Li et al. [134] & $\begin{array}{l}\text { Aged APPswe/PSEN1 double-transgenic } \\
\text { mice }\end{array}$ & $A D$ & Decreased expression of Tet2 \\
\hline
\end{tabular}

5-hmC 5-hydroxymethylcytosine, $A D$ Alzheimer's disease, aMCl amnestic mild cognitive impairment, APP amyloid precursor protein, BACE1 $\beta$-site APP cleaving enzyme I, BDNF brain-derived neurotrophic factor, MeCP2 methyl-CpG-binding protein 2, PARK2 Parkin RBR E3 ubiquitin protein ligase, PD Parkinson's disease, PINK1 PTENinduced putative kinase 1, PSEN1 presenilin 1, SOD2 superoxide dismutase 2, Tet2 ten-eleven translocation methyl cytosine dioxygenases 
Table 2 Physical exercise alters the levels of proteins related with neurodegeneration

\begin{tabular}{|c|c|c|c|}
\hline References & Subjects & Intervention (duration/speed) & Observations \\
\hline Ma et al. [129] & $\begin{array}{l}\text { Adult male Wister rats with transient } \\
\text { focal cerebral ischemia }\end{array}$ & $\begin{array}{l}\text { Treadmill training: } 3 \text { days, } 7 \text { days, and } \\
2 \text { weeks, respectively, } 12 \mathrm{~m} / \mathrm{min} \text { for } \\
30 \text { min each day, } 5 \text { days a week }\end{array}$ & $\begin{array}{l}\text { Reduce the overexpression of TLR-2, TLR- } \\
4, \mathrm{NF}-\mathrm{KB} \text { and MyD88 in rat brain tissues }\end{array}$ \\
\hline Herring et al. [87] & 210-day-old female TgCRND8 mice & Running wheels: 5 months & $\begin{array}{l}\text { Reduce } A \beta \text { plaque burden and enhanced } \\
A \beta \text { clearance }\end{array}$ \\
\hline Tapia-Rojas et al. [88] & APPswe/PS1 $\triangle$ E9 mice & Voluntary wheel running: 10 weeks & $\begin{array}{l}\text { Decrease } A \beta \text { burden and } A \beta \text { oligomers in } \\
\text { the hippocampus }\end{array}$ \\
\hline Luo et al. [98] & $\begin{array}{l}\text { Male Sprague-Dawley rats (16- } \\
18 \text { months old) }\end{array}$ & $\begin{array}{l}\text { Swimming exercise: } 30 \text { min per day, } \\
5 \text { days per week, } 10 \text { weeks }\end{array}$ & $\begin{array}{l}\text { Upregulate the mRNA expressions of } \\
\text { Parkin }\end{array}$ \\
\hline Alkadhi and Dao [89] & $\begin{array}{l}\text { 7-week-old male Wistar rats: } 2 \text { weeks of } \\
\text { A } \beta \text { infusion ( } 250 \mathrm{pmol} / \text { day })\end{array}$ & $\begin{array}{l}\text { Treadmill exercise: } 10-15 \mathrm{~m} / \mathrm{min} \text {, } \\
4 \text { weeks }\end{array}$ & $\begin{array}{l}\text { Prevent the increase in the levels of APP, } \\
\text { BACE1 and A } \beta \text { proteins in both the CA1 } \\
\text { and DG areas }\end{array}$ \\
\hline Daniele et al. [96] & $\begin{array}{l}\text { Endurance athletes (mean age } \\
\quad 41.4 \pm 13.7 \text { years) }\end{array}$ & Endurance athletes & $\begin{array}{l}\text { Reduce the levels of total and oligomeric } \\
\text { a-synuclein }\end{array}$ \\
\hline $\begin{array}{l}\text { Jessop and Toledo- } \\
\text { Rodriguez [100] }\end{array}$ & $\begin{array}{l}\text { C57BL/J6 male ( } 3 \text { months and } \\
18 \text { months old) mice }\end{array}$ & Running wheel: 4 weeks & $\begin{array}{l}\text { Restore the age-related decrease in hip- } \\
\text { pocampal Tet1 and Tet2 expression }\end{array}$ \\
\hline Wu et al. [120] & Sporadic AD rat model & Swimming exercise: 4 weeks & $\begin{array}{l}\text { Induce the DNA-binding activity of Nrf2 } \\
\text { and expression of downstream anti- } \\
\text { oxidant gene Sod2 in the hippocampal } \\
\text { CA1 region }\end{array}$ \\
\hline El Hayek et al. [80] & Adult male C57BL/6 mice & Voluntary running wheel: 30 days & Increase $B d n f$ expression \\
\hline Lourenco et al. [147] & $\mathrm{AD}$ model mice & $\begin{array}{l}\text { Swimming exercise: } 60 \text { min per session, } \\
5 \text { days per week for } 5 \text { weeks }\end{array}$ & $\begin{array}{l}\text { FNDC5/irisin mediates the protective } \\
\text { effects of PE on synaptic plasticity and } \\
\text { memory defects in } A D\end{array}$ \\
\hline Just-Borras et al. [154] & ALS model mice & $\begin{array}{l}\text { Treadmill training, swimming training: } \\
30 \text { min a day, } 5 \text { days a week, from } 70 \\
\text { until } 115 \text { days of age }\end{array}$ & $\begin{array}{l}\text { Maintain the BDNF/TrkB signaling at the } \\
\text { neuromuscular junction }\end{array}$ \\
\hline
\end{tabular}

$A \beta$ amyloid protein, $A L S$ amyotrophic lateral sclerosis, DG dentate gyrus, FNDC5 fibronectin type III domain-containing $5 /$ irisin, MyD88 myeloid differentiation $88, N F-$ $K B$ nuclear factor-kappa B, Nrf2 nuclear factor erythroid 2-related factor 2, PE physical exercise, PS1 presenilin 1, TLR-2 toll-like receptor 2, TLR-4 toll-like receptor 4, TrkB tyrosine receptor kinase $B$

neuropathological biomarkers, and may exacerbate the typical symptoms of declined global cognitive functioning, episodic memory, and working memory [30].

The biomarker- and symptom-related epigenetic age acceleration not only implies the close connection between $\mathrm{AD}$ progression and epigenetic clock, but also reveals changes in methylation levels of candidate genes. The pathogenic mutations of the APP gene, which are the hereditary basis for familial $\mathrm{AD}$, include considerable demethylation and increased expression [32]. As a membrane protein, APP concentrates in synapses of neurons and three enzymes (named $\alpha-, \beta-$, and $\gamma$-secretases) participate in its proteolysis. In contrast to $\alpha$-secretase, which is involved in healthy brain activity, successive cleavage of APP by $\beta$ - and $\gamma$-secretases leads to the generation of neurotoxic $A \beta$ [33]. The expression levels of these enzymes are controlled by methylation, which thereby regulates the disease progression. The overexpression of $\beta$-secretase, also known as $\beta$-site APP cleaving enzyme I $(B A C E 1)$, is associated with hypomethylation of enhancer regions in the DSCAML1 intron 3 that interact with the $B A C E 1$ gene promoter in $\mathrm{AD}$ neurons [8]. Additionally, as part of the $\gamma$-secretase complex, presenilin 1 (PSEN1) is often observed with decreased methylation. In $\mathrm{AD}$ post-mortem human brains, the lower methylation of PSEN1 compared to healthy controls contributes to higher expression of PSEN1 that exacerbates neurodegeneration [34]. On the other hand, the most clinically relevant genetic risk factor for sporadic $\mathrm{AD}$ is $A P O E$ gene mutation [35]. Higher DNAm levels across the promoter region of the $A P O E$ gene may raise the risk of dementia and AD [36].

PD is another common neurodegenerative disease that has the fastest-growing prevalence, causing increased disability and death [37]. The main features of PD include the massive loss of DAergic neurons in the substantia nigra pars compact (SNpc), which causes blockage of dopaminergic afferent nerves in the basal ganglia and striatum $[38,39]$. With the progressive deficiency of the DA system, the presence of cytoplasmic inclusion bodies (i.e., Lewy bodies, mainly composed of $\alpha$-synuclein) in the residual neurons of the substantia nigra is considered as a prominent pathological change in PD. The accumulation of $\alpha$-synuclein eventually leads to death and functional loss of DAergic neurons [40]. SNCA encodes for $\alpha$-synuclein and is the first pathogenic gene discovered in 
familial PD. SNCA has been found to have dysregulated expression due to the abnormal methylation at its CpG sites [41, 42], which ultimately influences the content of Lewy bodies. Furthermore, additional PD-associated pathogenic genes can control the onset and progression of Parkinsonism. For example, PTEN-induced putative kinase 1 (PINK1) is a disease-causing gene that is involved in $\alpha$-synuclein aggregation and regulation of dopaminergic neuronal homeostasis [43]. PINK1 is a crucial biomarker that links mitochondrial dysfunction with PD pathogenesis [44]. Hypermethylation of PINK1 plays a crucial role in the etiology of early-onset PD [45]. Parkin, another PD-associated pathogenic gene located downstream of PINK1, functions in basal mitophagy by eliminating the damaged mitochondria to prevent inflammation and neurodegeneration [46]. A growing body of evidence implicates that mutations in PINK1 are not only present in autosomal dominant, familial cases of PD, but also detected in sporadic PD patients [44, 47]. Given that only $\sim 15 \%$ of PD patients have the monogenic origin and comprehensive epigenetic alterations are often observed in the genes described above, integration of DNAm data related to gene expression is essential for the identification of overlaps between sporadic and monogenic phenotypes [44].

Although the physiological changes and pathological causes of the above conditions are partially different, there are some common mechanisms in the epigeneticsrelated cerebral damage response. For example, a recent study identified 130 differentially expressed genes between $\mathrm{AD}$ cases and controls across four brain regions (the hippocampus, entorhinal cortex [EC], dorsolateral prefrontal cortex [PFC], and cerebellum), and found that the expression of these genes is associated with DNAm sites, which are overrepresented in AD genetic risk loci [48]. In addition, two loci (17q11.2 and 1p36.12) have been identified to be associated with epigenetic age acceleration of the PFC, and more importantly, the foundations of brain aging [49]. These results imply that DNAm is the underpinning of pathological and molecular changes in cognition-related brain regions. The concrete molecular mechanisms involve alterations of the DNAm profile in memory-related genes by DNA methyltransferase (DNMT) 3a2 [50], whose expression is reduced with aging in the hippocampus [51]. Furthermore, overexpression of neuronal DNMT3a2 leads to stable memory engrams and improves memory performance [50], implying a close relationship between DNAm and synaptic plasticity in neurodegeneration. The epigenetic states in neurodegeneration-affected patients and aging populations are both different from that in the general population and are associated with the methylation-related enzymes.
Generally, the process of DNAm refers to the covalent bonding between the methyl donor S-adenosyl methionine (SAM) and the cytosine of the genome CpG dinucleotide, catalyzed by DNMTs, thereby regulating gene expression (Fig. 2) [52, 53]. DNMTs are a family of enzymes that include DNMT1, DNMT3a, and DNMT3b. The de novo methylases DNMT3a and DNMT3b transfer methyl groups to unmodified DNA strands, while the maintenance methylase DNMT1 is recruited to the newly synthesized daughter strand during DNA replication to promote a fully methylated state [54]. In certain cases of neurodegeneration, DNMTs show differential expression and enzymatic activities [55]. For example, current research suggests that the expression of DNMT1 decreases significantly from birth to senescence, and this is further supported by a comparison of hippocampal DNMT1 content between 3- and 20-month-old rats, and by data from aged $5 \times$ FAD mice $[56,57]$. However, the level of DNMT1 has been reported to be significantly increased in 2-month-old AD transgenic mice [57]. The increase in DNMT1 during the initial stage of AD may be protective against the harmful effects that occur with $A D$. Thus, DNMT1 shows time-dependent level of expression in different life stages and diseases. In contrast, DNMT1 expression in the striatum increases with aging [58], indicating a regional specific pattern of DNMT1 expression.

The demethylation of 5-methylcytosine $(5-\mathrm{mC})$ is mostly catalyzed by the ten-eleven translocation (TET) enzymes, including Tet1, Tet2, and Tet3. 5-Hydroxymethylcytosine $(5-\mathrm{hmC})$ is the first oxidative product in the active demethylation of $5-\mathrm{mC}$, and is abundant in the $\mathrm{CNS}$ and functions to regulate neurodevelopment and synaptic function $[59,60]$. The $5-\mathrm{hmC}$ is now recognized as an important epigenetic marker in neurodegenerative diseases due to the significant differences in its level and TET expression between normal and pathological conditions [60]. In the hippocampus of $\mathrm{AD}$ patients, 5-mC and 5 -hmC are robustly reduced, showing a significant negative correlation with amyloid plaque. Therefore, the progression of $\mathrm{AD}$ is accompanied by aberrant epigenetic signatures [61].

As a reader of DNAm, the enzyme methyl-CpG-binding protein 2 (MeCP2) can recognize the methyl-CpGbinding domain, and protect conversion of $5-\mathrm{mC}$ to 5 -hmC [62]. In addition, MeCP2 participates in neurodevelopment and maintains normal functions of the CNS by regulating DNAm dynamics, where both over- and under-expression of MeCP2 may lead to neuropsychiatric disorders [63]. Although $\mathrm{MeCP} 2$ is a classical pathogenic gene of Rett syndrome, a rare neurodevelopmental disorder [64], studies have revealed that it is also dysregulated in $\mathrm{AD}$ and $\mathrm{PD}[65,66]$. Specifically, MeCP2 can bind to promoters at $5-\mathrm{mC}$ regions to transcriptionally inhibit 


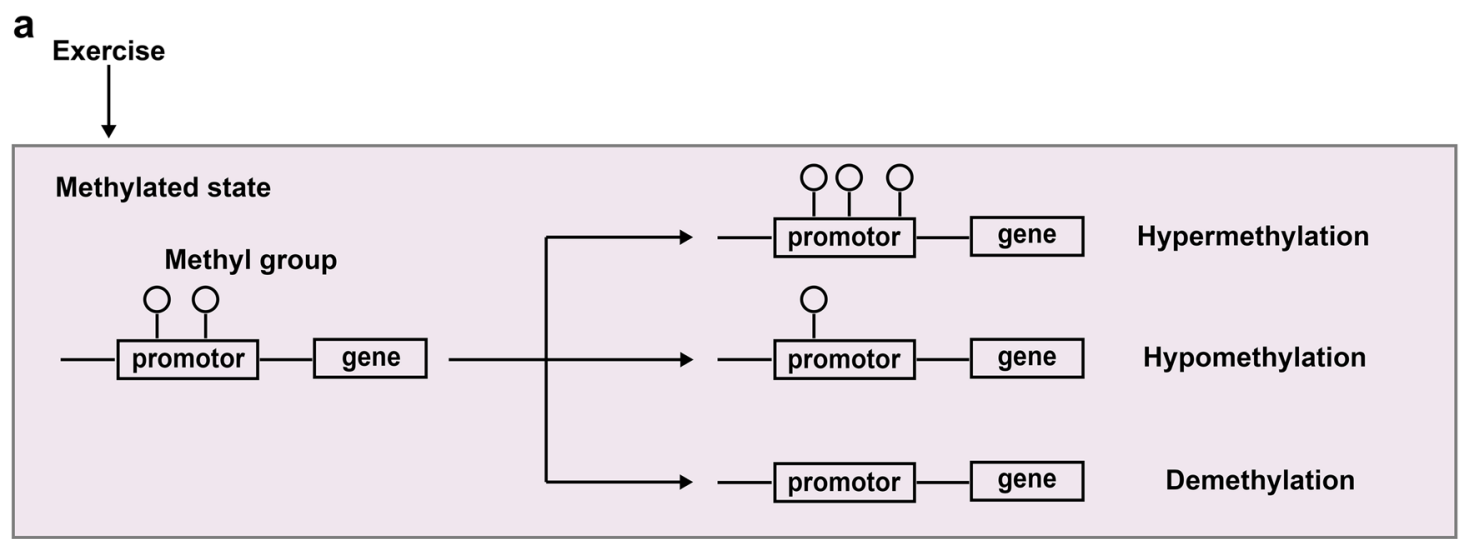

b<smiles>Cn1ccc(N)nc1=O</smiles>

C

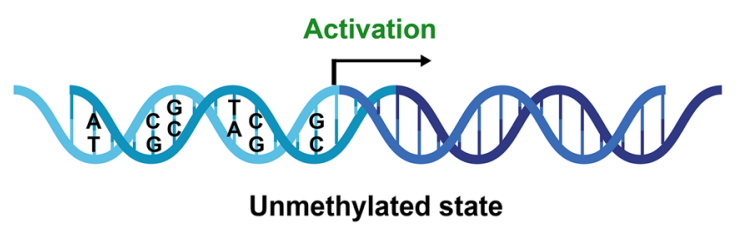

Demethylated state

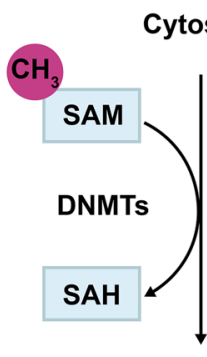<smiles>Cc1cn(C)c(=O)nc1N</smiles>

5-mc<smiles>Cn1cc(CO)c(N)nc1=O</smiles>

5-hmc

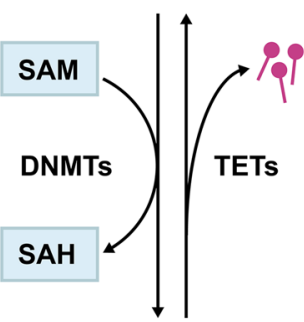

Methylated state

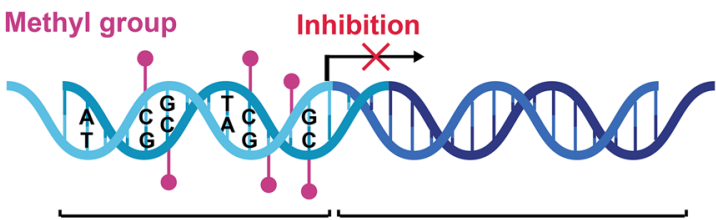

Promotor

\section{Target gene}

Fig. 2 Exercise alters the state of DNAm. (a) Physical exercise changes the state of DNAm including hypermethylation, hypomethylation and demethylation to influence the expression of genes. $(\mathbf{b}, \mathbf{c})$ DNAm refers to the covalent bonding between a methyl group from $\mathrm{S}$ adenosyl methionine (SAM) and the carbon-5 position of cytosine in the genome CpG dinucleotide (catalyzed by DNMTs). 5-Hydroxymethylcytosine (5-hmC) is an intermediate during active DNA demethylation. The conversion of 5-mC to 5-hmC is mediated by TETs. DNAm generally leads to gene silencing, but the phenomenon is reversed in a demethylated state

the expression of neurotrophin-like brain-derived neurotrophic factor (BDNF) [67]. A study has reported that APP/PS1 AD mice have decreased expression of MeCP2 and phosphorylated-cAMP response element-binding protein (p-CREB, an upstream factor of BDNF) in the hippocampus, suggesting the involvement of $\mathrm{MeCP} 2 / \mathrm{p}-$ CREB in neurodegeneration by regulating the expression of neurotrophins [68].

\section{Exercise as an epigenetic protector against brain aging and neurodegeneration}

As an external environmental modulator, PE has been confirmed to show beneficial effects against aging by increasing neuro-vascularization, neurogenesis, and neurotrophic factor synthesis [63, 69, 70]. Besides, as brain aging is also closely related to telomere length, which provides some indications of cell lifespan [71], a key goal 
of PE implementation is to increase telomerase activities and telomere lengths [72]. Telomerase reverse transcriptase (TERT), the catalytic subunit of telomerase, can influence the telomere-synthesizing DNA and maintain telomere stability [73]. However, TERT has been discovered to advance intrinsic epigenetic age acceleration in primary fibroblasts (although not in the brain), opposing its function in promoting proliferation [74].

Besides the example of telomeres, a recently published review summarizes a diverse set of circulating factors, such as BDNF, fibronectin type III domain-containing $5 /$ irisin (FNDC5/irisin), and ketone bodies, that are affected by endurance exercise to counter age-related changes [75]. BDNF is required for almost all important cerebral functions, and plays multiple roles in the adult nervous system to support the survival, differentiation, and plasticity of existing neurons [76]. It also plays a regulatory role in neurodevelopment and synaptic transmission [76, 77]. Therefore, the progressive and dramatic decline of BDNF induced by brain aging is an important target for regulation. Since the first report of a positive correlation between exercise and BDNF mRNA level in rodents in 1995, a large number of studies have revealed the mechanisms underlying the effect of exercise on the epigenetics of BDNF [78-80], which controls BDNF expression and thereby regulates its functions in the brain $[81,82]$. Specifically, there is a negative correlation between DNAm and BDNF expression, and aging induces increased methylation in $B d n f$ exons/promoters I, II, and IV in the orbital frontal cortex [83]. To a certain extent, exercise could positively contribute to the maintenance and improvement of brain health by modulating BDNF expression in the brain.

Both clinical and animal evidence has revealed that PE is an efficient therapeutic option for $\mathrm{AD}$, with limited adverse effects reported in patients [84, 85]. PE alleviates the disease symptoms and delays the onset of cognitive deficits by directly counteracting Alzheimer-like pathologies [86, 87]. After 10 weeks of voluntary wheel training, the two major pathological biomarkers of $\mathrm{AD}$, aggregated $A \beta$ and phosphorylated Tau proteins, are significantly reduced in the hippocampus of a transgenic APP/PS1 mouse model. In addition, AD mice with running training demonstrate improved spatial memory and reduced neuron loss [88]. The expressions of $A P P, B A C E 1$, and $P S E N 1$ in early-onset $\mathrm{AD}$, or $A P O E$ in late-onset $\mathrm{AD}$, are also regulated by exercise to varying degrees to alleviate the pathological symptoms of AD [89-91].

Aerobic exercise for 3 months in PD patients can effectively increase the evoked dopamine release in the caudate nucleus and the responsivity of the ventral striatum [92]. Moreover, regular PE leads to improvements in motor disorders (including tremor, cerebellar ataxia, and muscle rigidity) and non-motor performances (including autonomic dysfunction and cognitive deficits) in patients with mild to moderate PD [93-95]. Higher physical activity, rather than low levels of PE, can change the methylation status of SNCA and reduce the expression of both total and oligomeric $\alpha$-synuclein [96]. PE also activates the PINK1/Parkin pathway to enhance mitophagy activity, which further promotes mitochondrial fitness and finally preserves cognitive function in the aged brain $[97$, 98].

Interestingly, researchers have found that PE is capable of controlling DNAm by regulating various enzymes to delay the processes of aging and neurodegeneration. For example, a single exercise session can decrease DNMT1 and DNMT3b levels in the hippocampus of young adult rats, but not in the aged group. The levels of the two enzymes remain unchanged in the aged rats even with a longer duration of an exercise protocol (i.e., chronic treadmill training) [56]. As a result, PE may not affect the expression and transcriptional activity of DNMTs in the aging brain but instead, may function as a neurodegenerative modulator that regulates the methylation of related genes (e.g., $B D N F$ ). In contrast to the regulation of DNMTs, the activity of DNA demethylation-related enzymes is directly regulated by PE in aged animals. A previous study showed that a 2-week, voluntary wheel training in sedentary rats increases the level of hippocampal Tet1 [99]. Additionally, 4-week PE counteracts the decreased Tet 1 and Tet 2 expression induced by aging, through enhancing the hippocampal 5-hmC content, thus promoting cognitive functions of aged mice [100]. In addition, PE can increase the level of activated MeCP2 that is closely related with BDNF expression. After 7 days of wheel running exercise, the phospho-MeCP2 level is upregulated, resulting in dissociation of $\mathrm{MeCP} 2$ from the $B d n f$ promoter, leading to $B d n f$ gene transcription [101].

\section{DNAm for neuroplasticity, neuronal loss and neurogenesis under exercise}

The primary symptoms of neurodegenerative diseases are progressive cognitive decline and memory loss, which are mainly regulated by neuroplasticity, an adaptive ability to change brain structure and function in response to environmental stimulations [102]. It is well known that the hippocampus and the cortical region covering the PFC and the EC are commonly associated with learning and memory $[103,104]$. Recent studies have shown that PE at a proper intensity can increase the volumes of the right and the left dorsolateral PFC, thereby interfering with the brain volume shrinkage that is commonly seen in aging populations, preventing the age-related deterioration of brain structures $[105,106]$. Voluntary running can also enhance neurogenesis, which accelerates the recovery of 
synaptic plasticity from saturation to normality, and ultimately results in complete recovery of memory capacity [107]. It is evident that both MeCP2 and TETs serve as essential mediators of the hippocampus-dependent memory, such as regulations of LTP/LTD and excitatory synaptogenesis [108-110], and are positively modulated by exercise [101, 111, 112]. In conclusion, DNAm and demethylation are the keys to PE-related regulation of synaptic plasticity, promotion of memory encoding, and amelioration of cognitive defects.

Neurodegenerative diseases often eventually lead to loss of neuronal structures and functions. Neuronal death, whether apoptosis or necrosis, is caused by a variety of mechanisms related to DNAm. Studies on genetic and environmental factors in neurodegenerative diseases have shown that the imbalance between oxidative and antioxidant systems, caused by the increase in reactive oxygen species (ROS) and the deficiency of antioxidant capacity, is the main contributor to oxidative stress [113], which ultimately leads to neuronal death [113, 114]. Treadmill exercise can reverse the related neuronal loss by preventing oxidative damage of DNA [115]. In healthy cells, many important antioxidant-related factors and enzymes, such as nuclear factor erythroid 2-related factor 2 (Nrf2) and superoxide dismutase 2 (SOD2), are present and involved in defending against oxidative damage $[116,117]$. In neurodegeneration, the decreased expression and function of such molecules is usually mediated by DNAm $[118,119]$. In an AD rat model, exercise pretreatment significantly improves the protein level and DNA-binding activity of Nrf2, further promoting the expression of downstream antioxidant genes such as $S O D 2$, leading to resistance to oxidative stress [120]. In an animal model of impaired redox homeostasis, occupancy of DNMT3b at SOD2 promoter causes hypermethylation at this site, and this hypermethylation is relieved after DNMT inhibition by a pan DNMT inhibitor, which relieves the oxidative damage and the deficits in learning and memory [119].

Neuroinflammation is a self-defensive response of the nervous system to harmful stimuli, and is persisting and hyperactive in neurodegenerative diseases throughout pathological progression. Apart from the role in restoring age-related deficits in cognition, PE can also suppress inappropriate neuroinflammation and its successive reactions by reducing the quantity of senescent microglia and increasing their phagocytic capacity [121]. The response of microglia to inflammatory stimuli is epigenetically regulated by MeCP2. MeCP2 deficiency promotes the transition of microglia into an active state and subsequently leads to microglia depletion as disease progresses [122]. Microglial activation triggers immune responses through the toll-like receptor 4 (TLR-4), a key regulator of the transcriptional factor nuclear factor-kappa B (NF$\kappa B)$ in the innate immune system [123]. Subsequently, a wide variety of inflammatory cytokines are released. The activation of TLR-4 stimulates myeloid differentiation 88 (MyD88) and TNF receptor-associated factor 6 (TRAF6), which promote NF-kB release by phosphorylating the inhibitor of NF-kB (IкB) [124-127]. Interestingly, the activation of NF- $\mathrm{kB}$ decreases the expression of TET genes and thus induces mild aberration of methylation. Moreover, the enzymatic activities of DNMTs are upregulated as a result of the overproduction of nitric oxide (NO) in inflamed tissues. These two conditions synergistically cause abnormal methylation, which serves as an important mechanism underlying the involvement of chronic inflammation in neurodegenerative diseases [128]. Sufficient evidence has validated that PE can regulate the expression of TLR4, MyD88, TRAF6, and NF- $\mathrm{KB}$ in this signaling cascade [129-131]. Thus, the epigenetic regulation of neuroinflammatory proteins may underlie the effect of PE in decreasing neuroinflammation and its associated neuronal death.

PE alleviates the negative effects of DNAm associated with neurodegeneration and also regulates neuronal survival. DNMTs are involved in the regulation of neuronal survival and in the methylation processes in aging- and disease-related neurodegeneration. DNMT1 deficiency can counteract the age-related decline of cortical inhibitory interneurons in the cerebral cortex, as proved by DNMT1-deficient mice, which show increased interneuron survival and decreased age-related transcriptional changes [132]. This implies that DNMT1 is implicated in the reversal of the epigenetic clock by modulating age-related genes. While PE is ineffective in regulating DNMTs in older rats as depicted earlier [56], it is speculated that PE may indirectly affect these enzymes due to their critical role in neuronal survival and methylation. In addition to DNMTs, overexpression of Tet2 in the aged hippocampus can also counteract the decline in neurogenesis by increasing 5 -hmC levels [133]. In middle-aged $2 \times \mathrm{Tg}$ - AD mice, over-expression of Tet 2 in the dentate gyrus (DG) improves memory impairment and reduces amyloid burden [134], suggesting a neuroprotective role of Tet2 in neuronal survival. However, a recent study has found that the increased Tet 2 modifies the enhancer sites in PD neurons to give rise to a loss of nigral dopaminergic neurons, while Tet 2 depletion reverses the phenomenon [135]. Thus, the effect and activity of Tet2 may be regionally or neuronally specific.

In addition to maintaining neuronal viability, PE also promotes neurogenesis for neuronal renewal. Radial neural stem/precursor cells (rNSPCs) are quiescent under normal conditions and are regarded as a latent reservoir for neurons that participate in neurogenesis 
[136, 137]. Studies have found that exercise could transit rNSPCs from quiescence to an active state and induce their entry into the cell cycle [138]. Exercise can increase neurogenesis and ameliorate cognitive decline through a liver-to-brain axis, as an increase in liver-derived circulating blood factor glycosylphosphatidylinositol-specific phospholipase D1 (Gpld1) and several activated coagulation and complement signaling cascades have been identified in the brain after exercise [70]. Our previous work has revealed the activation of rNSPCs in the DG region, which is mediated by long-term excitation of hippocampal dentate granule cells upon 30 consecutive days of voluntary running in mice. By downregulating the ephrin-B-EphB transcellular signaling, this exercise training promotes the transition of quiescent rNSPCs and their acquisition of neuronal fate [137]. When subjected to certain stimuli, these activated rNSPCs may undergo asymmetrical division, giving rise to rapidly proliferating amplifying neural progenitors, which immediately differentiate into neurons [139]. The intrinsic state of rNSPC, whether quiescent or active, can be determined by the relative level of cellular ROS content. Physical activity drives ROS fluctuation to prepare rNSPCs to enter the cell cycle. Subsequently, the cells with lower ROS content exit the quiescent state and transform to a state with proliferative and differentiative activity [140].

PE not only promotes NSPC differentiation into neurons, but also maintains the homeostasis of the stem cell pool $[137,141]$. The rNSPC pool declines with time after initial activation, which, together with brain aging, leads to impairment of hippocampal neurogenesis [139, 142]. In the aging hippocampus, oscillations of glucocorticoid hormones (GCs) prevent the activation of NSPCs induced by the glucocorticoid receptor (GR)GC pathway, regulate their proliferation, and preserve a quiescent NSPC pool. This effect is mediated by the GC oscillation-induced changes in methylation of specific gene promoters associated with cell cycle regulation, and the maintenance of stable DNMT expression [143]. Interestingly, only oscillatory GCs (but not continuous GCs) show sensitivity to cell cycle entry, proliferation, and cell cycle exit [143]. Although evidence has shown that PE can induce the elevation of basal GC levels [144], the potential of $\mathrm{PE}$ in promoting GC oscillations remains unknown.

\section{The epigenetic clock of the muscle-brain crosstalk}

$\mathrm{PE}$ induces muscle contraction and elicits muscle-brain signal transmission, during which myokines are secreted from muscle cells as an important element of the endocrine loop to stabilize the muscle-brain connection [63].

As a newly discovered myokine peptide, the soluble irisin is a cleaved and secreted fragment of FNDC5, and serves as a messenger molecule that is transmitted from muscles to various body tissues during exercise. Irisin also regulates neurogenesis, behavior, and metabolism in the brain $[145,146]$. Peripheral overexpression of FNDC5/irisin in the livers of mice rescues the AD-associated memory defects, indicating that peripheral irisin may reach the brain and potentially mediate the neuroprotective actions of PE [147]. Remarkably, DNAm in the CpG island of the FNDC5 promoter regulates FNDC5 mRNA expression in the human liver through the binding of the transcription factor GR complex to the targeted FNDC5 gene [148]. In AD patients and mice, the levels of FNDC5/irisin in the brain and cerebrospinal fluid are significantly reduced, leading to impaired synaptic plasticity and memory. Yet, these alterations are reversed by exercise [147]. During PE, peripheral delivery of FNDC5 boosts blood irisin and further induces the expression of neuroprotective genes including $B d n f$ in the hippocampus [149]. Therefore, FNDC5/irisin serves as a crucial mediator of the beneficial effects of $\mathrm{PE}$ on cognition, suggesting that both peripheral and CNS FNDC5/irisin are potential targets for AD treatment [147]. Tracing back to its sources, FNDC5 gene expression is regulated by a transcriptional co-activator, peroxisome proliferatoractivated receptor gamma coactivator 1-alpha (PGC-1 $\alpha$ ). PGC- $1 \alpha$ is induced in muscles by exercise and mediates many biological processes related to energy metabolism [145]. In human skeletal muscles, PE reduces the methylation level of the $P G C-1 \alpha$ promoter in an intensitydependent manner, which leads to an increase in mRNA level [150]. PGC-1 $\alpha$ deficiency causes neurodegenerative damage and reduces the expression of neuronal FNDC5 and BDNF in the brain $[149,151]$. Therefore, the PGC-1 $\alpha-$ FNDC5-BDNF pathway is an important regulator in the muscle-brain crosstalk.

In addition to the neuronal origin of BDNF that is regulated by PGC- $1 \alpha-\mathrm{FNDC} 5 /$ Irisin [149], BDNF is also directly secreted as a myokine from muscle cells during $\mathrm{PE}$ in response to muscle contraction. A meta-analysis has reported that the peripheral BDNF level in older adults (aged $\geq 60$ years) can be increased by a variety of $\mathrm{PE}$, thereby exerting neuroprotective effects on the brain [152]. The muscle-derived BDNF is capable of remodeling neuromuscular synapses and connections between motor neurons and muscles [153]. In the context of neurodegeneration, a lack of BDNF would exacerbate the age-related decline of muscle mass and function, as well as the loss of neuromuscular junctions. Exercise intervention can reverse many physiological changes associated with BDNF decline in peripheral blood, thereby supporting motoneuron survival in older adults [152, 154]. Besides the alterations in intracerebral BDNF, the differential methylation of the $B d n f$ gene in blood is 
considered as a biomarker of AD [155]. Both the transition from healthy state to dementia and the development from aMCI to $\mathrm{AD}$ are accompanied by increased methylation at the $B d n f$ promoter in blood [155-157], suggesting that the expression of peripheral BDNF changes with progression of pathology.

\section{Epigenetic modulation to reverse motor deficits}

While it is tempting to conclude that the connection between DNAm and PE largely lies in the alteration of DNAm, this is not the case. In reality, DNAm can influence motor abilities and modulate behaviors reversely to sustain normal movements. For example, deletion of DNMT3a in AgRP neurons can reduce voluntary exercise behavior by disrupting the expression of genes that are characteristic of AgRP neurons in the arcuate nucleus of the hypothalamus [158].

The normal locomotor activity is balanced by DNMT3a levels, where both deficiency and overexpression of DNMT3a may lead to negative consequences. Knockout of DNMT3a interferes with the development of motor neurons and causes defects in neuralization [159], whereas overexpression of DNMT3a induces apoptosis of motor neurons in the mouse spinal cord and human motor cortex, leading to neurodegeneration [55]. On the contrary, excessive expression of DNMT3a2 and its partner DNMT3L driven by the dopamine transporter promotor activates the nigrostriatal pathway to improve locomotor function and spontaneous activity of DA neurons [160]. Interestingly, ablation of muscle-specific DNMT3a only influences the expression of genes involved in muscle development but does not alter the exercise capacity [161]. This suggests that DNMT3a regulates the movement ability through motor-related neurons in the brain rather than through mature skeletal muscles. Therefore, similar to the regulation of DNMTs by $\mathrm{PE}$, the reverse modulation of motor deficits also has a clear regional specificity.

In dopaminergic neurons derived from induced pluripotent stem cells from patients with parkin (PARK2) gene mutations, there is hypomethylation of individual CpG sites at the catechol-O-methyltransferase (COMT) gene promotor, and increased expression of COMT [162]. In addition, overexpression of COMT in dopaminergic neurons of the substantia nigra induces impaired synaptic dopamine transmission and produces cataleptic behaviors that are associated with impaired motor coordination in the initial PD stages. Therefore, COMT upregulation may be regarded as an initial dysregulation in PD [162]. In addition, downregulation of Tet2 in the SNpc can reverse the PD-induced motor deficits and dopaminergic neuronal injury [163].
Huntington's disease (HD) is another common neurodegenerative condition with motor deficits, which is associated with mutations of the expanded cytosineadenine-guanine (CAG) repeats in the huntingtin (HTT) gene. Similar to AD and PD, HD also exhibits an accelerated epigenetic age. Only the CpGs located in proximity (within $2 \mathrm{~kb}$ ) to the CAG expansion in exon 1 of $H T T$ are significantly hypermethylated in HD, which exhibit positive correlations with severe motor progression in patients [164, 165]. Amyotrophic lateral sclerosis (ALS) is the most common neurodegenerative disease of the motor neuron system, which is generally caused by mutations in the chromosome 9 open reading frame (C9orf72) gene [166]. Hexanucleotide repeat expansion of $C 9$ orf 72 causes downstream molecular aberrations and leads to overt cellular toxicity [167]. C9orf72 promoter hypermethylation induces transcriptional silencing of C9orf 72 , which could maintain motor neuronal survival and serve as an endogenous protective regulator of neuropathology $[167,168]$. In conclusion, most neurodegenerative diseases are related to epigenetic changes (i.e., hypomethylation and hypermethylation) in pathogenesis. Epigenetic alterations could be a therapeutic target to ameliorate the disease-related symptoms including movement disorders.

\section{Considerations and prospects}

It is well known that PE is beneficial for brain health, yet it is influenced by a complex web of factors, which poses challenges for researchers to pinpoint the most appropriate exercise proposal. For example, PE influences neural mechanisms in an intensity-dependent manner. The cortical and subcortical brain regions respond more strongly to low-intensity exercise (ratings of perceived exertion [RPE] 6-12 on the Borg Scale) than to high-intensity exercise. Moreover, the cerebellum is only activated by low-intensity exercise. In contrast, the cognition-related area PFC shows reduced activation in low-intensity exercise, which is further exacerbated in high-intensity exercise (RPE 13-17) [169] as it may lead to body instability and stress responses $[169,170]$. The benefit of low-intensity exercise has also been demonstrated in other performances. Compared with a running training at $20 \mathrm{~m} / \mathrm{min}$, the ischemia rats trained at $8 \mathrm{~m} / \mathrm{min}$ show better spatial memory, enhanced hippocampal dendritic complexity, and increased BDNF level [170]. Yet, the positive effects of high-intensity training should not be undervalued, as high-intensity interval training shows greater enhancement of motor cortex plasticity compared with moderate exercise [171]. In addition to intensity, there are also concerns regarding the safety of training and the selection of exercise mode and duration. Although the use of PE as a therapeutic treatment remains partially controversial, 
there is no doubt a positive effect of exercise in neurodegeneration. PE can interfere with the disease-specific mechanisms, including abnormal aggregation of $A \beta$ and $\mathrm{APP}$ in $\mathrm{AD}$ and functional loss of DA neurons in PD, which are correlated with DNAm in the epigenetic clock. The improvement of neurodegeneration by PE intervention is a time-dependent process, which alters the gene methylation differently at distinct disease stages. Besides, the expression of BDNF, which depends on the methylation level, is essential to most aspects of brain health and has regulatory effects on diverse cerebral functions both in the CNS and in the muscle-brain crosstalk. In DNAm and demethylation, the expression of essential enzymesDNMTs and TETs-is time-specific, brain regional specific, and neuronal specific. Therefore, special attention should be paid to distinguish and refine the brain areas and neuronal cell types, as well as the stages of aging and diseases, when studying the effects of PE on these enzymes. Furthermore, current research has suggested that exercise only affects DNMT levels in young adult mice but not in aging brains. This conclusion should be made with caution due to the regional specific expression of DNMTs and the limited number of studies available. Future studies are needed to test the effect of PE in the aging brain and investigate the action specificity of DNMTs. In addition, mechanisms underlying the alterations of related genes and proteins caused by DNAm are potential targets for PE treatment, which is of significance for both healthy individuals and patients with brain dysfunctions. Future studies should also examine other genes that may be regulated by DNAm, in order to identify novel targets of PE.

\section{Conclusions}

PE has a high potential for clinical improvement of symptoms of neurodegenerative diseases and for the reversal of aging, and prevention of age-related diseases. However, due to individual differences, the intensity of exercise has to be adjusted according to individual's physical qualifications, health status, and disease development. Limitations presented in literature and on clinical applications indicate that a future direction of research is to explore the well-defined boundaries of PE to guide optimal exercise prescription and maximize the safety of $\mathrm{PE}$ treatments.

\footnotetext{
Abbreviations

5-hmC: 5-Hydroxymethylcytosine; 5-mC: 5-Methylcytosine; A $\beta$ : Amyloid- $\beta$; AD: Alzheimer's disease; AE: Aerobic exercise; APP: Amyloid precursor protein; BACE1: $\beta$-Site APP cleaving enzyme l; BDNF: Brain-derived neurotrophic factor; CNS: Central nervous system; COMT: Catechol-O-methyltransferase; DG: Dentate gyrus; DNAm: DNA methylation; DNMT: DNA methyltransferase; EC: Entorhinal cortex; Gpld1: Glycosylphosphatidylinositol (GPI)-specific phospholipase D1; GR: Glucocorticoid receptor; HD: Huntington's disease; MyD88:
}

Myeloid differentiation 88; NF-kB: Nuclear factor-kappa B; NFT: Neurofibrillary tangles; Nrf2: Nuclear factor erythroid 2-related factor 2; NSPC: Neural stem/ progenitor cell; PD: Parkinson's disease; PE: Physical exercise; PFC: Prefrontal cortex; ROS: Reactive oxygen species; SAM: S adenosyl methionine; SNpc: Substantia nigra pars compacta; SOD2: Superoxide dismutase 2; TERT: Telomerase reverse transcriptase gene; TETs: Ten-eleven translocation methylcytosine dioxygenases; TLR-4: Toll-like receptor 4; TRAF6: TNF receptor-associated factor 6.

\section{Acknowledgements}

Not applicable.

\section{Authors' contributions}

NJX and XDL contributed to the conception of the article. MX performed literature research, drafted the manuscript and prepared the illustration. JYZ, MX, and NJX revised the manuscript. NJX and MYL reviewed and edited the manuscript before submission. All authors approved the final version.

\section{Funding}

This research was supported by the National Natural Science Foundation of China (31671062 and 81870820 to N.-J.X. 31900796 to X.-D. L), Shanghai Brain-Intelligence Project from the Science and Technology Commission of Shanghai Municipality (16JC1420500 and 18JC1420302), and the Innovative Research Team of High-level Local Universities in Shanghai.

Availability of data and materials

Not applicable.

\section{Declarations}

Ethics approval and consent to participate

Not applicable.

\section{Consent for publication}

Not applicable.

\section{Competing interests}

The authors declare no competing financial interests.

\section{Author details}

${ }^{1}$ Department of Anatomy, Histology and Embryology, Kunming Medical University, Kunming 650500, China. ${ }^{2}$ Collaborative Innovation Center for Brain Science, Department of Anatomy and Physiology, Shanghai Jiao Tong University School of Medicine, Shanghai 200025, China. ${ }^{3}$ Department of Neurology and Institute of Neurology, Rui Jin Hospital, Shanghai Jiao Tong University School of Medicine, Shanghai 200025, China. ${ }^{4}$ Shanghai Key Laboratory of Reproductive Medicine, Shanghai Jiao Tong University School of Medicine, Shanghai 200025, China. ${ }^{5}$ Key Laboratory of Cell Differentiation and Apoptosis of Chinese Ministry of Education, Shanghai Jiao Tong University School of Medicine, Shanghai 200025, China. ${ }^{6}$ Present Address: Department of Laboratory Medicine and Pathobiology, University of Toronto, Toronto, ON, Canada.

Received: 1 May 2021 Accepted: 29 July 2021

Published online: 13 August 2021

\section{References}

1. Schloss MJ, Swirski FK, Nahrendorf M. Modifiable cardiovascular risk, hematopoiesis, and innate immunity. Circ Res. 2020;126:1242-59.

2. Kerr J, Anderson C, Lippman SM. Physical activity, sedentary behaviour, diet, and cancer: an update and emerging new evidence. Lancet Oncol. 2017;18:e457-71.

3. Bangsbo J, Blackwell J, Boraxbekk CJ, Caserotti P, Dela F, Evans AB, et al. Copenhagen Consensus statement 2019: physical activity and ageing Br J Sports Med. 2019;53:856-8.

4. Amaro-Gahete FJ, De-la OA, Jurado-Fasoli L, Sanchez-Delgado G, Ruiz JR, Castillo MJ. Metabolic rate in sedentary adults, following different 
exercise training interventions: the FIT-AGEING randomized controlled trial. Clin Nutr. 2020;39:3230-40.

5. Valenzuela PL, Castillo-Garcia A, Morales JS, de la Villa P, Hampel H, Emanuele E, et al. Exercise benefits on Alzheimer's disease: State-of-thescience. Ageing Res Rev. 2020;62:101108.

6. Petzinger GM, Fisher BE, McEwen S, Beeler JA, Walsh JP, Jakowec MW. Exercise-enhanced neuroplasticity targeting motor and cognitive circuitry in Parkinson's disease. Lancet Neurol. 2013;12:716-26.

7. Barha CK, Davis JC, Falck RS, Nagamatsu LS, Liu-Ambrose T. Sex differences in exercise efficacy to improve cognition: a systematic review and meta-analysis of randomized controlled trials in older humans. Front Neuroendocrinol. 2017:46:71-85.

8. Singh AS, Saliasi E, van den Berg V, Uijtdewilligen L, de Groot RHM, Jolles J, et al. Effects of physical activity interventions on cognitive and academic performance in children and adolescents: a novel combination of a systematic review and recommendations from an expert panel. Br J Sports Med. 2019;53:640-7.

9. Perszyk DR, Waxman SR. Linking language and cognition in infancy. Annu Rev Psychol. 2018;69:231-50.

10. Diamond A. Executive functions. Annu Rev Psychol. 2013;64:135-68.

11. Langa KM, Levine DA. The diagnosis and management of mild cognitive impairment: a clinical review. JAMA. 2014;312:2551-61.

12. Rabin LA, Smart CM, Amariglio RE. Subjective cognitive decline in preclinical Alzheimer's disease. Annu Rev Clin Psychol. 2017;13:369-96.

13. Aarsland D, Creese B, Politis M, Chaudhuri KR, Ffytche DH, Weintraub $D$, et al. Cognitive decline in Parkinson disease. Nat Rev Neurol. 2017:13:217-31.

14. Whitty E, Mansour H, Aguirre E, Palomo M, Charlesworth G, Ramjee S, et al. Efficacy of lifestyle and psychosocial interventions in reducing cognitive decline in older people: systematic review. Ageing Res Rev. 2020;62:101113.

15. Larson EB, Wang L, Bowen JD, McCormick WC, Teri L, Crane P, et al. Exercise is associated with reduced risk for incident dementia among persons 65 years of age and older. Ann Intern Med. 2006;144:73-81.

16. Huang P, Fang R, Li BY, Chen SD. Exercise-related changes of networks in aging and mild cognitive impairment brain. Front Aging Neurosci. 2016;8:47.

17. Lardenoije R, latrou A, Kenis G, Kompotis K, Steinbusch HW, Mastroeni $D$, et al. The epigenetics of aging and neurodegeneration. Prog Neurobiol. 2015;131:21-64.

18. Cavalli G, Heard E. Advances in epigenetics link genetics to the environment and disease. Nature. 2019:571:489-99.

19. McEwen LM, O'Donnell KJ, McGill MG, Edgar RD, Jones MJ, Maclsaac $J L$, et al. The PedBE clock accurately estimates DNA methylation age in pediatric buccal cells. Proc Natl Acad Sci U S A. 2020;117:23329-35.

20. Horvath S. DNA methylation age of human tissues and cell types. Genome Biol. 2013;14:R115.

21. Shireby GL, Davies JP, Francis PT, Burrage J, Walker EM, Neilson GWA, et al. Recalibrating the epigenetic clock: implications for assessing biological age in the human cortex. Brain. 2020;143:3763-75.

22. Horvath S, Raj K. DNA methylation-based biomarkers and the epigenetic clock theory of ageing. Nat Rev Genet. 2018;19:371-84.

23. Yu M, Hazelton WD, Luebeck GE, Grady WM. Epigenetic aging: more than just a clock when it comes to cancer. Cancer Res. 2020;80:367-74.

24. Brooks-Wilson AR. Genetics of healthy aging and longevity. Hum Genet. 2013;132:1323-38.

25. Yeshurun S, Hannan AJ. Transgenerational epigenetic influences of paternal environmental exposures on brain function and predisposition to psychiatric disorders. Mol Psychiatry. 2019;24:536-48.

26. McGee SL, Hargreaves M. Epigenetics and exercise. Trends Endocrinol Metab. 2019;30:636-45.

27. Hou Y, Dan X, Babbar M, Wei Y, Hasselbalch SG, Croteau DL, et al. Ageing as a risk factor for neurodegenerative disease. Nat Rev Neurol. 2019:15:565-81.

28. Singh T, Yadav S. Role of microRNAs in neurodegeneration induced by environmental neurotoxicants and aging. Ageing Res Rev. 2020;60:101068

29. Ohia-Nwoko O, Montazari S, Lau YS, Eriksen JL. Long-term treadmill exercise attenuates tau pathology in P301S tau transgenic mice. Mol Neurodegen. 2014;9:54
30. Levine ME, Lu AT, Bennett DA, Horvath S. Epigenetic age of the prefrontal cortex is associated with neuritic plaques, amyloid load, and Alzheimer's disease related cognitive functioning. Aging (Albany NY). 2015;7:1198-211

31. Zhang M, Dilliott AA, Khallaf R, Robinson JF, Hegele RA, Comishen M, et al. Genetic and epigenetic study of an Alzheimer's disease family with monozygotic triplets. Brain. 2019;142:3375-81.

32. Hou Y, Chen H, He Q, Jiang W, Luo T, Duan J, et al. Changes in methylation patterns of multiple genes from peripheral blood leucocytes of Alzheimer's disease patients. Acta Neuropsychiatr. 2013;25:66-76.

33. Zhou R, Yang G, Guo X, Zhou Q, Lei J, Shi Y. Recognition of the amyloid precursor protein by human gamma-secretase. Science. 2019;363:eaaw930.

34. Monti N, Cavallaro RA, Stoccoro A, Nicolia V, Scarpa S, Kovacs GG, et al. CpG and non-CpG Presenilin1 methylation pattern in course of neurodevelopment and neurodegeneration is associated with gene expression in human and murine brain. Epigenetics. 2020;15:781-99.

35. Lin YT, Seo J, Gao F, Feldman HM, Wen HL, Penney J, et al. APOE4 causes widespread molecular and cellular alterations associated with Alzheimer's disease phenotypes in human iPSC-derived brain cell types. Neuron. 2018;98:1141-54.

36. Karlsson IK, Ploner A, Wang Y, Gatz M, Pedersen NL, Hagg S. Apolipoprotein E DNA methylation and late-life disease. Int J Epidemiol. 2018:47:899-907.

37. Yang W, Hamilton JL, Kopil C, Beck JC, Tanner CM, Albin RL, et al. Current and projected future economic burden of Parkinson's disease in the U.S NPJ Parkinsons Dis. 2020;6:15

38. Alexander GE. Biology of Parkinson's disease: pathogenesis and pathophysiology of a multisystem neurodegenerative disorder. Dialogues Clin Neurosci. 2004;6:259-80.

39. Dauer W, Przedborski S. Parkinson's disease: mechanisms and models. Neuron. 2003;39:889-909.

40. Bourdenx M, Nioche A, Dovero S, Arotcarena ML, Camus S, Porras $\mathrm{G}$, et al. Identification of distinct pathological signatures induced by patient-derived alpha-synuclein structures in nonhuman primates. Sci Adv. 2020;6:eaaz9165.

41. Mohd Murshid N, Aminullah Lubis F, Makpol S. Epigenetic changes and its intervention in age-related neurodegenerative diseases. Cell Mol Neurobiol. 2020. https://doi.org/10.1007/s10571-020-00979-z.

42. Tan YY, Wu L, Zhao ZB, Wang Y, Xiao Q, Liu J, et al. Methylation of alpha-synuclein and leucine-rich repeat kinase 2 in leukocyte DNA of Parkinson's disease patients. Parkinsonism Relat Disord. 2014:20:308-13.

43. Creed RB, Goldberg MS. Enhanced susceptibility of PINK1 knockout rats to alpha-synuclein fibrils. Neuroscience. 2020;437:64-75.

44. Malpartida AB, Williamson M, Narendra DP, Wade-Martins R, Ryan BJ. Mitochondrial dysfunction and mitophagy in Parkinson's disease: from mechanism to therapy. Trends Biochem Sci. 2020;46:329-43.

45. Tarale P, Sivanesan S, Daiwile AP, Stoger R, Bafana A, Naoghare PK, et al. Global DNA methylation profiling of manganese-exposed human neuroblastoma SH-SY5Y cells reveals epigenetic alterations in Parkinson's disease-associated genes. Arch Toxicol. 2017:91:2629-41.

46. Sliter DA, Martinez J, Hao L, Chen X, Sun N, Fischer TD, et al. Parkin and PINK1 mitigate STING-induced inflammation. Nature. 2018:561:258-62.

47. Fernandez-Santiago R, Merkel A, Castellano G, Heath S, Raya A, Tolosa E, et al. Whole-genome DNA hyper-methylation in iPSC-derived dopaminergic neurons from Parkinson's disease patients. Clin Epigenetics. 2019:11:108

48. Semick SA, Bharadwaj RA, Collado-Torres L, Tao R, Shin JH, Deep-Soboslay $A$, et al. Integrated DNA methylation and gene expression profiling across multiple brain regions implicate novel genes in Alzheimer's disease. Acta Neuropathol. 2019;137:557-69.

49. Lu AT, Hannon E, Levine ME, Crimmins EM, Lunnon K, Mill J, et al. Genetic architecture of epigenetic and neuronal ageing rates in human brain regions. Nat Commun. 2017:8:15353.

50. Gulmez Karaca K, Kupke J, Brito DVC, Zeuch B, Thome C, Weichenhan $D$, et al. Neuronal ensemble-specific DNA methylation strengthens engram stability. Nat Commun. 2020;11:639.

51. Oliveira AM, Hemstedt TJ, Bading H. Rescue of aging-associated decline in Dnmt3a2 expression restores cognitive abilities. Nat Neurosci. 2012:15:1111-3. 
52. Furukawa A, Walinda E, Arita K, Sugase K. Structural dynamics of double-stranded DNA with epigenome modification. Nucleic Acids Res. 2021:49:1152-62

53. Sanchez-Romero MA, Casadesus J. The bacterial epigenome. Nat Rev Microbiol. 2020;18:7-20

54. Moore LD, Le T, Fan G. DNA methylation and its basic function. Neuropsychopharmacology. 2013;38:23-38.

55. Chestnut BA, Chang Q, Price A, Lesuisse C, Wong M, Martin LJ. Epigenetic regulation of motor neuron cell death through DNA methylation. J Neurosci. 2011;31:16619-36.

56. Elsner VR, Lovatel GA, Moyses F, Bertoldi K, Spindler C, Cechinel LR, et al. Exercise induces age-dependent changes on epigenetic parameters in rat hippocampus: a preliminary study. Exp Gerontol. 2013;48:136-9.

57. Grinan-Ferre C, Sarroca S, Ivanova A, Puigoriol-Illamola D, Aguado F, Camins $A$, et al. Epigenetic mechanisms underlying cognitive impairment and Alzheimer disease hallmarks in 5XFAD mice. Aging (Albany NY). 2016;8:664-84.

58. Fasolino M, Liu S, Wang Y, Zhou Z. Distinct cellular and molecular environments support aging-related DNA methylation changes in the substantia nigra. Epigenomics. 2017;9:21-31.

59. Khare T, Pai S, Koncevicius K, Pal M, Kriukiene E, Liutkeviciute Z, et al. 5-hmC in the brain is abundant in synaptic genes and shows differences at the exon-intron boundary. Nat Struct Mol Biol. 2012;19:1037-43.

60. Cheng Y, Bernstein A, Chen D, Jin P. 5-Hydroxymethylcytosine: a new player in brain disorders? Exp Neurol. 2015;268:3-9.

61. Chouliaras L, Mastroeni D, Delvaux E, Grover A, Kenis G, Hof PR, et al. Consistent decrease in global DNA methylation and hydroxymethylation in the hippocampus of Alzheimer's disease patients. Neurobiol Aging. 2013;34:2091-9.

62. Szulwach KE, Li X, Li Y, Song CX, Wu H, Dai Q, et al. 5-hmC-mediated epigenetic dynamics during postnatal neurodevelopment and aging. Nat Neurosci. 2011;14:1607-16.

63. Pedersen BK. Physical activity and muscle-brain crosstalk. Nat Rev Endocrinol. 2019;15:383-92.

64. Jorge-Torres OC, Szczesna K, Roa L, Casal C, Gonzalez-Somermeyer L, Soler $\mathrm{M}$, et al. Inhibition of Gsk3b reduces Nfkb1 signaling and rescues synaptic activity to improve the rett syndrome phenotype in Mecp2knockout mice. Cell Rep. 2018;23:1665-77.

65. Xie T, Zhang J, Yuan X, Yang J, Ding W, Huang X, et al. Is X-linked methylCpG binding protein 2 a new target for the treatment of Parkinson's disease. Neural Regen Res. 2013;8:1948-57.

66. Xie AJ, Hou TY, Xiong W, Huang HZ, Zheng J, Li K, et al. Tau overexpression impairs neuronal endocytosis by decreasing the GTPase dynamin 1 through the miR-132/MeCP2 pathway. Aging Cell. 2019;18:e12929.

67. Chang Q, Khare G, Dani V, Nelson S, Jaenisch R. The disease progression of Mecp2 mutant mice is affected by the level of BDNF expression. Neuron. 2006:49:341-8.

68. Choi J, Kwon HJ, Lee JE, Lee Y, Seoh JY, Han PL. Hyperoxygenation revitalizes Alzheimer's disease pathology through the upregulation of neurotrophic factors. Aging Cell. 2019;18:e12888.

69. Morland C, Andersson KA, Haugen OP, Hadzic A, Kleppa L, Gille A, et al. Exercise induces cerebral VEGF and angiogenesis via the lactate receptor HCAR1. Nat Commun. 2017:8:15557.

70. Horowitz AM, Fan X, Bieri G, Smith LK, Sanchez-Diaz Cl, Schroer AB, et al. Blood factors transfer beneficial effects of exercise on neurogenesis and cognition to the aged brain. Science. 2020;369:167-73.

71. Franke K, Bublak P, Hoyer D, Billiet T, Gaser C, Witte OW, et al. In vivo biomarkers of structural and functional brain development and aging in humans. Neurosci Biobehav Rev. 2020;117:142-64.

72. Werner CM, Hecksteden A, Morsch A, Zundler J, Wegmann M, Kratzsch $J$, et al. Differential effects of endurance, interval, and resistance training on telomerase activity and telomere length in a randomized, controlled study. Eur Heart J. 2019;40:34-46.

73. Shay JW. Role of telomeres and telomerase in aging and cancer. Cancer Discov. 2016;6:584-93.

74. Lu AT, Xue L, Salfati EL, Chen BH, Ferrucci L, Levy D, et al. GWAS of epigenetic aging rates in blood reveals a critical role for TERT. Nat Commun. 2018:9:387.

75. Jachim SK, Sakamoto AE, Zhang X, Pearsall VM, Schafer MJ, LeBrasseur NK. Harnessing the effects of endurance exercise to optimize cognitive health: fundamental insights from Dr. Mark P. Mattson. Ageing Res Rev. 2020;64:101147.

76. Song M, Martinowich K, Lee FS. BDNF at the synapse: why location matters. Mol Psychiatry. 2017;22:1370-5.

77. Tanila H. The role of BDNF in Alzheimer's disease. Neurobiol Dis. 2017;97:114-8.

78. Walsh El, Smith L, Northey J, Rattray B, Cherbuin N. Towards an understanding of the physical activity-BDNF-cognition triumvirate: a review of associations and dosage. Ageing Res Rev. 2020;60:101044.

79. Neeper SA, Gomez-Pinilla F, Choi J, Cotman C. Exercise and brain neurotrophins. Nature. 1995;373:109.

80. El Hayek L, Khalifeh M, Zibara V, Abi Assaad R, Emmanuel N, Karnib N, et al. Lactate mediates the effects of exercise on learning and memory through SIRT1-dependent activation of hippocampal brain-derived neurotrophic factor (BDNF). J Neurosci. 2019;39:2369-82.

81. de Meireles LCF, Galvao F Jr, Walker DM, Cechinel LR, de Souza Grefenhagen Al, Andrade G, et al. Exercise modalities improve aversive memory and survival rate in aged rats: role of hippocampal epigenetic modifications. Mol Neurobiol. 2019;56:8408-19.

82. Boschen KE, McKeown SE, Roth TL, Klintsova AY. Impact of exercise and a complex environment on hippocampal dendritic morphology, Bdnf gene expression, and DNA methylation in male rat pups neonatally exposed to alcohol. Dev Neurobiol. 2017;77:708-25.

83. McKinney BC, Lin CW, Oh H, Tseng GC, Lewis DA, Sibille E. Hypermethylation of BDNF and SST genes in the orbital frontal cortex of older individuals: a putative mechanism for declining gene expression with age. Neuropsychopharmacology. 2015;40:2604-13.

84. Duzel E, van Praag H, Sendtner M. Can physical exercise in old age improve memory and hippocampal function? Brain. 2016;139:662-73.

85. Pitkala KH, Poysti MM, Laakkonen ML, Tilvis RS, Savikko N, Kautiainen H, et al. Effects of the Finnish Alzheimer disease exercise trial (FINALEX): a randomized controlled trial. JAMA Intern Med. 2013;173:894-901.

86. Brown BM, Peiffer J, Rainey-Smith SR. Exploring the relationship between physical activity, beta-amyloid and tau: a narrative review. Ageing Res Rev. 2019;50:9-18.

87. Herring A, Münster Y, Metzdorf J, Bolczek B, Krüssel S, Krieter D, et al. Late running is not too late against Alzheimer's pathology. Neurobiol Dis. 2016:94:44-54.

88. Tapia-Rojas C, Aranguiz F, Varela-Nallar L, Inestrosa NC. Voluntary running attenuates memory loss, decreases neuropathological changes and induces neurogenesis in a mouse model of Alzheimer's disease. Brain Pathol. 2016;26(1):62-74.

89. Alkadhi KA, Dao AT. Exercise decreases BACE and APP levels in the hippocampus of a rat model of Alzheimer's disease. Mol Cell Neurosci. 2018;86:25-9.

90. Soto I, Graham LC, Richter HJ, Simeone SN, Radell JE, Grabowska W, et al. APOE stabilization by exercise prevents aging neurovascular dysfunction and complement induction. PLOS Biol. 2015;13:e1002279.

91. Brown BM, Sohrabi HR, Taddei K, Gardener SL, Rainey-Smith SR, Peiffer $J$ J, et al. Habitual exercise levels are associated with cerebral amyloid load in presymptomatic autosomal dominant Alzheimer's disease. Alzheimers Dement. 2017;13:1197-206.

92. Sacheli MA, Neva JL, Lakhani B, Murray DK, Vafai N, Shahinfard E, et al. Exercise increases caudate dopamine release and ventral striatal activation in Parkinson's disease. Mov Disord. 2019;34:1891-900.

93. Ellis T. Exercise in Parkinson's disease: are we narrowing in on the essential elements? Lancet Neurol. 2019;18:982-3.

94. Mak MK, Wong-Yu IS, Shen X, Chung CL. Long-term effects of exercise and physical therapy in people with Parkinson disease. Nat Rev Neurol. 2017:13:689-703.

95. Petzinger GM, Fisher BE, McEwen S, Beeler JA, Walsh JP, Jakowec MW. Exercise-enhanced neuroplasticity targeting motor and cognitive circuitry in Parkinson's disease. Lancet Neurol. 2013;12(7):716-26.

96. Daniele S, Costa B, Pietrobono D, Giacomelli C, lofrida C, Trincavelli ML, et al. Epigenetic modifications of the alpha-synuclein gene and relative protein content are affected by ageing and physical exercise in blood from healthy subjects. Oxid Med Cell Longev. 2018;2018:3740345.

97. Zhao N, Xia J, Xu B. Physical exercise may exert its therapeutic influence on Alzheimer's disease through the reversal of mitochondrial dysfunction via SIRT1-FOXO1/3-PINK1-Parkin-mediated mitophagy. J Sport Health Sci. 2021;10:1-3. 
98. Luo L, Dai JR, Guo SS, Lu AM, Gao XF, Gu YR, et al. Lysosomal proteolysis is associated with exercise-induced improvement of mitochondrial quality control in aged hippocampus. J Gerontol A Biol Sci Med Sci. 2017;72:1342-51.

99. Solvsten CAE, de Paoli F, Christensen JH, Nielsen AL. Voluntary physical exercise induces expression and epigenetic remodeling of VegfA in the rat hippocampus. Mol Neurobiol. 2018;55:567-82.

100. Jessop P, Toledo-Rodriguez M. Hippocampal TET1 and TET2 expression and DNA hydroxymethylation are affected by physical exercise in aged mice. Front Cell Dev Biol. 2018;6:45.

101. Gomez-Pinilla F, Zhuang Y, Feng J, Ying Z, Fan G. Exercise impacts brainderived neurotrophic factor plasticity by engaging mechanisms of epigenetic regulation. Eur J Neurosci. 2011;33:383-90.

102. Cramer SC, Sur M, Dobkin BH, O'Brien C, Sanger TD, Trojanowski $\mathrm{JQ}$, et al. Harnessing neuroplasticity for clinical applications. Brain. 2011;134:1591-609.

103. Eichenbaum H. Prefrontal-hippocampal interactions in episodic memory. Nat Rev Neurosci. 2017:18:547-58.

104. Basu J, Zaremba JD, Cheung SK, Hitti FL, Zemelman BV, Losonczy A, et al. Gating of hippocampal activity, plasticity, and memory by entorhinal cortex long-range inhibition. Science. 2016;351:aaa5694.

105. Northey JM, Rattray B, Pumpa KL, Pryor DJ, Fraser MA, Shaw ME, et al. Objectively measured physical activity is associated with dorsolateral prefrontal cortex volume in older adults. Neuroimage. 2020;221:117150.

106. Di Loreto S, Falone S, D'Alessandro A, Santini S Jr, Sebastiani P, Cacchio $M$, et al. Regular and moderate exercise initiated in middle age prevents age-related amyloidogenesis and preserves synaptic and neuroprotective signaling in mouse brain cortex. Exp Gerontol. 2014;57:57-65.

107. Alam MJ, Kitamura T, Saitoh Y, Ohkawa N, Kondo T, Inokuchi K. Adult neurogenesis conserves hippocampal memory capacity. J Neurosci. 2018:38:6854-63.

108. Li H, Zhong X, Chau KF, Williams EC, Chang Q. Loss of activity-induced phosphorylation of MeCP2 enhances synaptogenesis. LTP and spatial memory Nat Neurosci. 2011;14:1001-8.

109. Rudenko A, Dawlaty MM, Seo J, Cheng AW, Meng J, Le T, et al. Tet1 is critical for neuronal activity-regulated gene expression and memory extinction. Neuron. 2013;79:1109-22.

110. Sun Z, Xu X, He J, Murray A, Sun MA, Wei X, et al. EGR1 recruits TET1 to shape the brain methylome during development and upon neuronal activity. Nat Commun. 2019;10:3892.

111. Pareja-Galeano H, Sanchis-Gomar F, Garcia-Gimenez JL. Physical exercise and epigenetic modulation: elucidating intricate mechanisms. Sports Med. 2014;44:429-36.

112. Zhang J, Li J, Zhu Y, Miao Z, Tian Y. Forced running exercise mitigates radiation-induced cognitive deficits via regulated DNA hydroxymethylation. Epigenomics. 2020;12:385-96.

113. Gamez-Valero A, Guisado-Corcoll A, Herrero-Lorenzo M, SolagurenBeascoa M, Marti E. Non-coding RNAs as sensors of oxidative stress in neurodegenerative diseases. Antioxidants (Basel). 2020;9:1095.

114. Grinan-Ferre C, Bellver-Sanchis A, Izquierdo V, Corpas R, Roig-Soriano J, Chillon $\mathrm{M}$, et al. The pleiotropic neuroprotective effects of resveratrol in cognitive decline and Alzheimer's disease pathology: from antioxidant to epigenetic therapy. Ageing Res Rev. 2021;67:101271.

115. Lu Y, Dong Y, Tucker D, Wang R, Ahmed ME, Brann D, et al. Treadmill exercise exerts neuroprotection and regulates microglial polarization and oxidative stress in a streptozotocin-induced rat model of sporadic Alzheimer's disease. J Alzheimers Dis. 2017;56:1469-84.

116. Kahroba H, Ramezani B, Maadi H, Sadeghi MR, Jaberie H, Ramezani F. The role of Nrf2 in neural stem/progenitors cells: from maintaining stemness and self-renewal to promoting differentiation capability and facilitating therapeutic application in neurodegenerative disease. Ageing Res Rev. 2021;65:101211.

117. Hussain A, Pooryasin A, Zhang M, Loschek LF, La Fortezza M, Friedrich $A B$, et al. Inhibition of oxidative stress in cholinergic projection neurons fully rescues aging-associated olfactory circuit degeneration in Drosophila. Elife. 2018:7:e32018.

118. Grinan-Ferre C, Puigoriol-Illamola D, Palomera-Avalos V, Perez-Caceres D, Companys-Alemany J, Camins A, et al. Environmental enrichment modified epigenetic mechanisms in SAMP8 mouse hippocampus by reducing oxidative stress and inflammaging and achieving neuroprotection. Front Aging Neurosci. 2016;8:241.
119. Balasubramanian N, Sagarkar S, Choudhary AG, Kokare DM, Sakharkar AJ. Epigenetic blockade of hippocampal SOD2 via DNMT3b-mediated DNA methylation: implications in mild traumatic brain injury-induced persistent oxidative damage. Mol Neurobiol. 2021;58(3):1162-84.

120. Wu C, Yang L, Tucker D, Dong Y, Zhu L, Duan R, et al. Beneficial effects of exercise pretreatment in a sporadic Alzheimer's rat model. Med Sci Sports Exerc. 2018;50:945-56.

121. Mela V, Mota BC, Milner M, McGinley A, Mills KHG, Kelly AM, et al. Exercise-induced re-programming of age-related metabolic changes in microglia is accompanied by a reduction in senescent cells. Brain Behav Immun. 2020;87:413-28.

122. Cronk JC, Derecki NC, Ji E, Xu Y, Lampano AE, Smirnov I, et al. Methyl-CpG binding protein 2 regulates microglia and macrophage gene expression in response to inflammatory stimuli. Immunity. 2015;42:679-91.

123. Qi J, Yu XJ, Fu LY, Liu KL, Gao TT, Tu JW, et al. Exercise training attenuates hypertension through TLR4/MyD88/NF-kappaB signaling in the hypothalamic paraventricular nucleus. Front Neurosci. 2019;13:1138.

124. Milanski M, Degasperi G, Coope A, Morari J, Denis R, Cintra DE, et al. Saturated fatty acids produce an inflammatory response predominantly through the activation of TLR4 signaling in hypothalamus: implications for the pathogenesis of obesity. J Neurosci. 2009;29:359-70.

125. Leitner GR, Wenzel TJ, Marshall N, Gates EJ, Klegeris A. Targeting toll-like receptor 4 to modulate neuroinflammation in central nervous system disorders. Expert Opin Ther Targets. 2019;23(10):865-82.

126. Lan X, Han X, Li Q, Li Q, Gao Y, Cheng T, et al. Pinocembrin protects hemorrhagic brain primarily by inhibiting toll-like receptor 4 and reducing M1 phenotype microglia. Brain Behav Immun. 2017;61:326-39.

127. Rangasamy SB, Jana M, Roy A, Corbett GT, Kundu M, Chandra S, et al. Selective disruption of TLR2-MyD88 interaction inhibits inflammation and attenuates Alzheimer's pathology. J Clin Invest. 2018;128:4297-312.

128. Takeshima H, Niwa T, Yamashita S, Takamura-Enya T, lida N, Wakabayashi $M$, et al. TET repression and increased DNMT activity synergistically induce aberrant DNA methylation. J Clin Invest. 2020;130:5370-9.

129. MaY, He M, Qiang L. Exercise therapy downregulates the overexpression of TLR4, TLR2, MyD88 and NF-kappaB after cerebral ischemia in rats. Int J Mol Sci. 2013;14:3718-33.

130. Ropelle ER, Flores MB, Cintra DE, Rocha GZ, Pauli JR, Morari J, et al. IL-6 and IL-10 anti-inflammatory activity links exercise to hypothalamic insulin and leptin sensitivity through IKKbeta and ER stress inhibition. PLoS Biol. 2010;8:e1000465.

131. Zhou J, Liu B, Liang C, Li Y, Song YH. Cytokine signaling in skeletal muscle wasting. Trends Endocrinol Metab. 2016;27:335-47.

132. Hahn A, Pensold D, Bayer C, Tittelmeier J, Gonzalez-Bermudez L, MarxBlumel L, et al. DNA methyltransferase 1 (DNMT1) function is implicated in the age-related loss of cortical interneurons. Front Cell Dev Biol. 2020:8:639.

133. Gontier G, Iyer M, Shea JM, Bieri G, Wheatley EG, Ramalho-Santos M, et al. Tet2 rescues age-related regenerative decline and enhances cognitive function in the adult mouse brain. Cell Rep. 2018;22:1974-81.

134. Li L, Miao M, Chen J, Liu Z, Li W, Qiu Y, et al. Role of Ten eleven translocation-2 (Tet2) in modulating neuronal morphology and cognition in a mouse model of Alzheimer's disease. J Neurochem. 2021;157(4):993-1012.

135. Marshall LL, Killinger BA, Ensink E, Li P, Li KX, Cui W, et al. Epigenomic analysis of Parkinson's disease neurons identifies Tet2 loss as neuroprotective. Nat Neurosci. 2020:23:1203-14.

136. Song J, Zhong C, Bonaguidi MA, Sun GJ, Hsu D, Gu Y, et al. Neuronal circuitry mechanism regulating adult quiescent neural stem-cell fate decision. Nature. 2012:489:150-4.

137. Dong J, Pan YB, Wu XR, He LN, Liu XD, Feng DF, et al. A neuronal molecular switch through cell-cell contact that regulates quiescent neural stem cells. Sci Adv. 2019;5(2):eaav4416.

138. Lugert S, Basak O, Knuckles P, Haussler U, Fabel K, Götz M, et al. Quiescent and active hippocampal neural stem cells with distinct morphologies respond selectively to physiological and pathological stimuli and aging. Cell Stem Cell. 2010;6:445-56.

139. Sierra A, Martín-Suárez S, Valcárcel-Martín R, Pascual-Brazo J, Aelvoet SA, Abiega $\mathrm{O}$, et al. Neuronal hyperactivity accelerates depletion of neural stem cells and impairs hippocampal neurogenesis. Cell Stem Cell. 2015;16:488-503. 
140. Adusumilli VS, Walker TL, Overall RW, Klatt GM, Zeidan SA, Zocher S, et al. ROS dynamics delineate functional states of hippocampal neural stem cells and link to their activity-dependent exit from quiescence. Cell Stem Cell. 2021;28:300-14.

141. Lugert S, Basak O, Knuckles P, Haussler U, Fabel K, Gotz M, et al. Quiescent and active hippocampal neural stem cells with distinct morphologies respond selectively to physiological and pathological stimuli and aging. Cell Stem Cell. 2010;6:445-56.

142. Encinas JM, Michurina TV, Peunova N, Park JH, Tordo J, Peterson DA, et al. Division-coupled astrocytic differentiation and age-related depletion of neural stem cells in the adult hippocampus. Cell Stem Cell. 2011;8:566-79.

143. Schouten M, Bielefeld P, Garcia-Corzo L, Passchier EMJ, Gradari S, Jungenitz $T$, et al. Circadian glucocorticoid oscillations preserve a population of adult hippocampal neural stem cells in the aging brain. Mol Psychiatry. 2020;25:1382-405.

144. Chen C, Nakagawa S, An Y, Ito K, Kitaichi Y, Kusumi I. The exercise-glucocorticoid paradox: how exercise is beneficial to cognition, mood, and the brain while increasing glucocorticoid levels. Front Neuroendocrinol. 2017:44:83-102.

145. Boström P, Wu J, Jedrychowski MP, Korde A, Ye L, Lo JC, et al. A PGC1-adependent myokine that drives brown-fat-like development of white fat and thermogenesis. Nature. 2012;481:463-8.

146. Zhang J, Zhang W. Can irisin be a linker between physical activity and brain function? Biomol Concepts. 2016;7:253-8.

147. Lourenco MV, Frozza RL, de Freitas GB, Zhang H, Kincheski GC, Ribeiro FC, et al. Exercise-linked FNDC5/irisin rescues synaptic plasticity and memory defects in Alzheimer's models. Nature Med. 2019;25:165-75.

148. Kim HK, Jeong YJ, Song IS, Noh YH, Seo KW, Kim M, et al. Glucocorticoid receptor positively regulates transcription of FNDC5 in the liver. Sci Rep. 2017;7:43296.

149. Wrann CD, White JP, Salogiannnis J, Laznik-Bogoslavski D, Wu J, Ma D, et al. Exercise induces hippocampal BDNF through a PGC-1 a/FNDC5 pathway. Cell Metab. 2013;18:649-59.

150. Barres R, Yan J, Egan B, Treebak JT, Rasmussen M, Fritz T, et al. Acute exercise remodels promoter methylation in human skeletal muscle. Cell Metab. 2012;15:405-11.

151. Ma D, Li S, Lucas EK, Cowell RM, Lin JD. Neuronal inactivation of peroxisome proliferator-activated receptor $\gamma$ coactivator 1a (PGC-1a) protects mice from diet-induced obesity and leads to degenerative lesions. J Biol Chem. 2010;285:39087-95.

152. Marinus N, Hansen D, Feys P, Meesen R, Timmermans A, Spildooren J. The impact of different types of exercise training on peripheral blood brain-derived neurotrophic factor concentrations in older adults: a meta-analysis. Sports Med. 2019;49:1529-46.

153. Delezie J, Weihrauch M, Maier G, Tejero R, Ham DJ, Gill JF, et al. BDNF is a mediator of glycolytic fiber-type specification in mouse skeletal muscle. Proc Natl Acad Sci U S A. 2019;116:16111-20.

154. Just-Borras L, Hurtado E, Cilleros-Mane V, Biondi O, Charbonnier F, Tomas $\mathrm{M}$, et al. Running and swimming prevent the deregulation of the BDNF/TrkB neurotrophic signalling at the neuromuscular junction in mice with amyotrophic lateral sclerosis. Cell Mol Life Sci. 2020:77:3027-40

155. Vasanthakumar A, Davis JW, Idler K, Waring JF, Asque E, Riley-Gillis $B$, et al. Harnessing peripheral DNA methylation differences in the Alzheimer's Disease Neuroimaging Initiative (ADNI) to reveal novel biomarkers of disease. Clin Epigenetics. 2020;12:84.

156. Fransquet PD, Lacaze P, Saffery R, Phung J, Parker E, Shah RC, et al. DNA methylation analysis of candidate genes associated with dementia in peripheral blood. Epigenomics. 2020;12:2109-23.
157. Xie B, Xu Y, Liu Z, Liu W, Jiang L, Zhang R, et al. Elevation of peripheral BDNF promoter methylation predicts conversion from amnestic mild cognitive impairment to Alzheimer's disease: a 5-year longitudinal study. J Alzheimers Dis. 2017;56:391-401.

158. MacKay H, Scott CA, Duryea JD, Baker MS, Laritsky E, Elson AE, et al. DNA methylation in AgRP neurons regulates voluntary exercise behavior in mice. Nat Commun. 2019:10:5364.

159. Ziller MJ, Ortega JA, Quinlan KA, Santos DP, Gu H, Martin EJ, et al. Dissecting the functional consequences of de novo DNA methylation dynamics in human motor neuron differentiation and physiology. Cell Stem Cell. 2018;22:559-74.

160. Cui D, Mesaros A, Burdeos G, Voigt I, Giavalisco P, Hinze Y, et al. Dnmt3a2/Dnmt3L Overexpression in the dopaminergic system of mice increases exercise behavior through signaling changes in the hypothalamus. Int J Mol Sci. 2020;21:6297.

161. Small L, Ingerslev LR, Manitta E, Laker RC, Hansen AN, Deeney B, et al. Ablation of DNA-methyltransferase 3A in skeletal muscle does not affect energy metabolism or exercise capacity. PLoS Genet. 2021;17:e1009325.

162. Kuzumaki N, Suda Y, Iwasawa C, Narita M, Sone T, Watanabe M, et al. Cell-specific overexpression of COMT in dopaminergic neurons of Parkinson's disease. Brain. 2019;142:1675-89.

163. Wu TT, Liu T, Li X, Chen YJ, Chen TJ, Zhu XY, et al. TET2-mediated Cdkn2A DNA hydroxymethylation in midbrain dopaminergic neuron injury of Parkinson's disease. Hum Mol Genet. 2020:29:1239-52.

164. Lu AT, Narayan P, Grant MJ, Langfelder P, Wang N, Kwak S, et al. DNA methylation study of Huntington's disease and motor progression in patients and in animal models. Nat Commun. 2020;11:4529.

165. Ruiz Buendia GA, Leleu M, Marzetta F, Vanzan L, Tan JY, Ythier V, et al. Three-dimensional chromatin interactions remain stable upon CAG/ CTG repeat expansion. Sci Adv. 2020;6:eaaz4012.

166. Appleby-Mallinder C, Schaber E, Kirby J, Shaw PJ, Cooper-Knock J, Heath PR, et al. TDP43 proteinopathy is associated with aberrant DNA methylation in human amyotrophic lateral sclerosis. Neuropathol Appl Neurobiol. 2021:47:61-72.

167. Liu EY, Russ J, Wu K, Neal D, Suh E, McNally AG, et al. C9orf72 hypermethylation protects against repeat expansion-associated pathology in ALS/FTD. Acta Neuropathol. 2014;128:525-41.

168. Cali CP, Park DS, Lee EB. Targeted DNA methylation of neurodegenerative disease genes via homology directed repair. Nucleic Acids Res. 2019;47:11609-22.

169. Fontes EB, Bortolotti H, Grandjean da Costa K, Machado de Campos B, Castanho GK, Hohl R, et al. Modulation of cortical and subcortical brain areas at low and high exercise intensities. Br J Sports Med. 2020;54:110-5.

170. Trivino-Paredes J, Patten AR, Gil-Mohapel J, Christie BR. The effects of hormones and physical exercise on hippocampal structural plasticity. Front Neuroendocrinol. 2016;41:23-43.

171. Andrews SC, Curtin D, Hawi Z, Wongtrakun J, Stout JC, Coxon JP. Intensity matters: high-intensity interval exercise enhances motor cortex plasticity more than moderate exercise. Cereb Cortex. 2020;30:101-12.

\section{Publisher's Note}

Springer Nature remains neutral with regard to jurisdictional claims in published maps and institutional affiliations. 